\title{
Healing times in a clinical case with similar and simultaneous lesions of hand and foot
}

Role of hydrostatic pressure in the development of venous ulcers.

\author{
S Ricci ${ }^{1}$, M Georgev ${ }^{2 \dagger}$

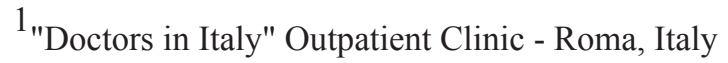 \\ $2{ }^{\dagger}$ Private practice Phlebologist - Latina, Italy
}

submitted: Dec 1, 2019, accepted: Mar 11, 2020, EPub Ahead of Print: Mar 30, 2020

Conflict of interest: None

DOI: 10.24019/jtavr.74 - Corresponding author:Prof. Stefano Ricci, varicci@tiscali.it

(C) 2019 Fondazione Vasculab impresa sociale ONLUS. All rights reserved.

\begin{abstract}
A curious case of contemporary skin lesion of hand and foot, showing the healing at the hand site versus worsening and inflammation at the foot after ten days, gives the occasion of analysing the different behaviour of the capillary circulation related to hydrostatic pressure (HP). In fact, HP at the foot, higher than at the hand, causes an increase of capillary pressure, accompanied by increase of transmicrovascular filtration while that arteriovenous pressure gradient is maintained; however, the accumulation of fluids is resisted by a number of edema safety factors that work in concert to limit edema formation (Lymphatic flow, decrease osmotic pressure, reduce the number of capillaries, myogenic constriction of arterioles, venous bulging). It seems evident that this complex balance may easily be broken by modern everyday life common events.
\end{abstract}

Keywords Hydrostatic pressure, foot lesions, edema, capillary circulation, ulcer healing

When invited to share my experience, my typical ppt presentation on varicose veins leg ulcers begins with a slide (stolen to my old friend Mihail Georgev $\uparrow 2010$ ) that shows the hand and foot of a foundry worker that was submitted to a spray of glowing material. In the photo taken 10 days after the event, we can see that the same lesion is nearly heeled at the hand sites while at the foot it is still present surrounded by inflammation and swelling, with no tendency to healing. (Fig 1)

I use this slide (like Mihail did) to introduce the concept that skin healing behavior is different in lower limbs compared to upper limbs even in the absence of venous insufficiency.

This difference is due mainly to the effect of hydrostatic pressure acting on the lower limbs and is the base of the well known ancient teaching that bed rest can heel the worst leg ulcers or simply eliminates ankle swelling. In similar cases an acute traumatic lesion having a long lasting healing time even in healthy subjects, may origin an "ulcer" (a skin lesion non healing after two weeks - https://www.circulationfoundation.org.uk/ help-advice/veins/leg-ulcers) or even "chronic ulcer"(a skin lesion that has no tendency to heal after 3 months of appropriate treatment - https://www.ncbi.nlm.nih.gov/pmc/ articles/PMC3087120). When a venous hypertension is already present, (reflux, obstruction, obesity, foot static disorders, musculo-skeletal diseases etc). the acute lesion will have more difficulty to heal than in a healthy ground.

In fact in the standing position the hydrostatic pressure (HP) acting on the lower part of the body is proportional to the distance from the right atrium, so that on the foot it will be of $80-90 \mathrm{mmHg}$ while at the hand it will be nearly absent or even negative (related to the hand position) ${ }^{1}$. Naturally the same occurs also in the lower limbs, if you change posture, though arms can move freely having a less important role in posture The same HP will act simultaneously on artery and veins so that arteriovenous gradient is maintained. Blood flow is then similar to the other parts of the body not submitted to HP, but to protect the tissues from this hypertension (with consequent plasma filtration rate increase) and possible edema formation a series 
of coordinated mechanisms (neurogenic vasocostriction, capillary vasomotion, endotelial cell activation, lymphatic activation) must take place, in particular if the calf muscle pump is inactive or not able, by ejecting the pooling blood, to lower the effects of $\mathrm{HP}^{1}$.

Changing position from lying to standing during 10 minutes is characterized by rapid increase of the leg volume ${ }^{2}$ in two phases: a fast one corresponding to venous compartments filling, and a slow one reflecting extravasation of plasma fluid from capillaries to the dependent tissues. The rate of change of leg (thigh + calf) volume is significantly correlated with the estimated loss of plasma volume ${ }^{3}$. Assessment of capillary fluid shifts during orthostatic stress in normal subjects and subjects with orthostatic intolerance showed that plasma volume fell by $13 \%$ ( $375 \pm 35 \mathrm{ml}$ plasma) over $14 \mathrm{~min}$, then it remained relatively stable. Ten to 20 min elapse before an apparent dynamic equilibrium is attained ${ }^{4}$. The resulting decrease in plasma volume causes hemoconcentration, including increases in hematocrit, hemoglobin, and plasma protein ${ }^{5}$. Moreover, under physiological conditions, endothelial cells have balanced anticoagulant and procoagulant properties.
Once exposed to injuries, such as high blood pressure or increased shear stress, several endothelial homeostatic mechanisms are physiologically activated and their procoagulant activity prevails ${ }^{6}$.

In prolonged standing (or hypomobility) additional progressive edema may appear.

In fact, increase of capillary pressure is accompanied by increase of transmicrovascular filtration but volume increase is opposed by a number of edema safety factors that work in concert to limit edema formation (lymphatic flow, decreased osmotic pressure, reduction of the number of capillaries, myogenic constriction of arterioles, venous bulging $)^{7}$. This explains why an elevation of venous pressure of $10-15 \mathrm{mmHg}$ may not cause edema formation, as it happens, at the opposite, when this limit is overwhelmed. .

The skin on the lower extremities contains a denser and more extensive network of lymphatic capillaries than the skin of the upper extremities which compensates the higher inflow of fluid in the interstitium caused by the effects of orthostatism. At the end of the process, edema occurs when lymphatic drainage is no more able to compensate for the interstitial fluid excess.

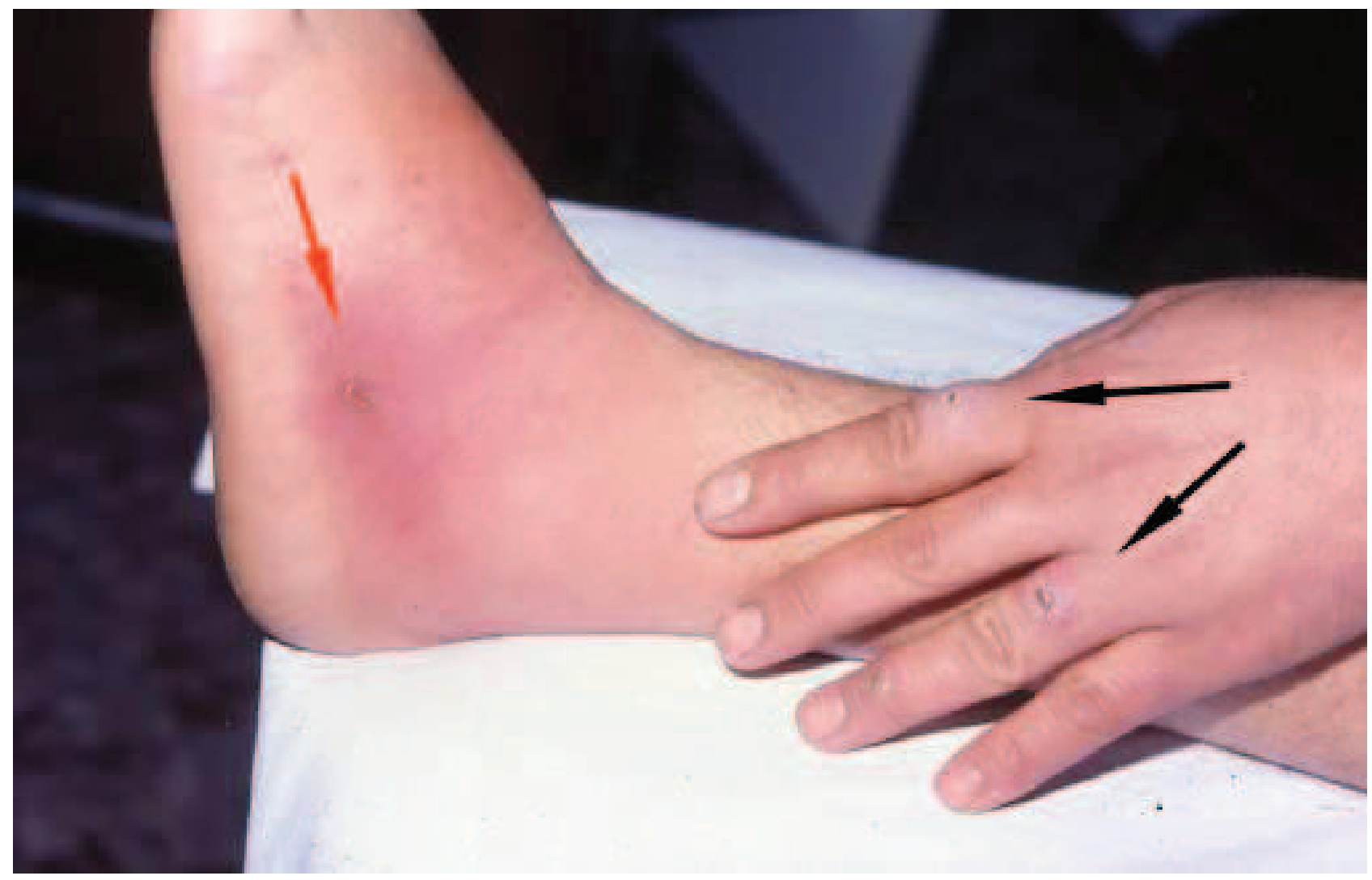

Figure 1 - The hand and foot of a foundry worker who was submitted to a spray of glowing material. A photo taken 10 days after the event shows that the same lesions are nearly heeled at the hand (black arrow) while at the foot the lesion is still present, surrounded by inflammation and swelling (red arrow), with no tendency to healing. 


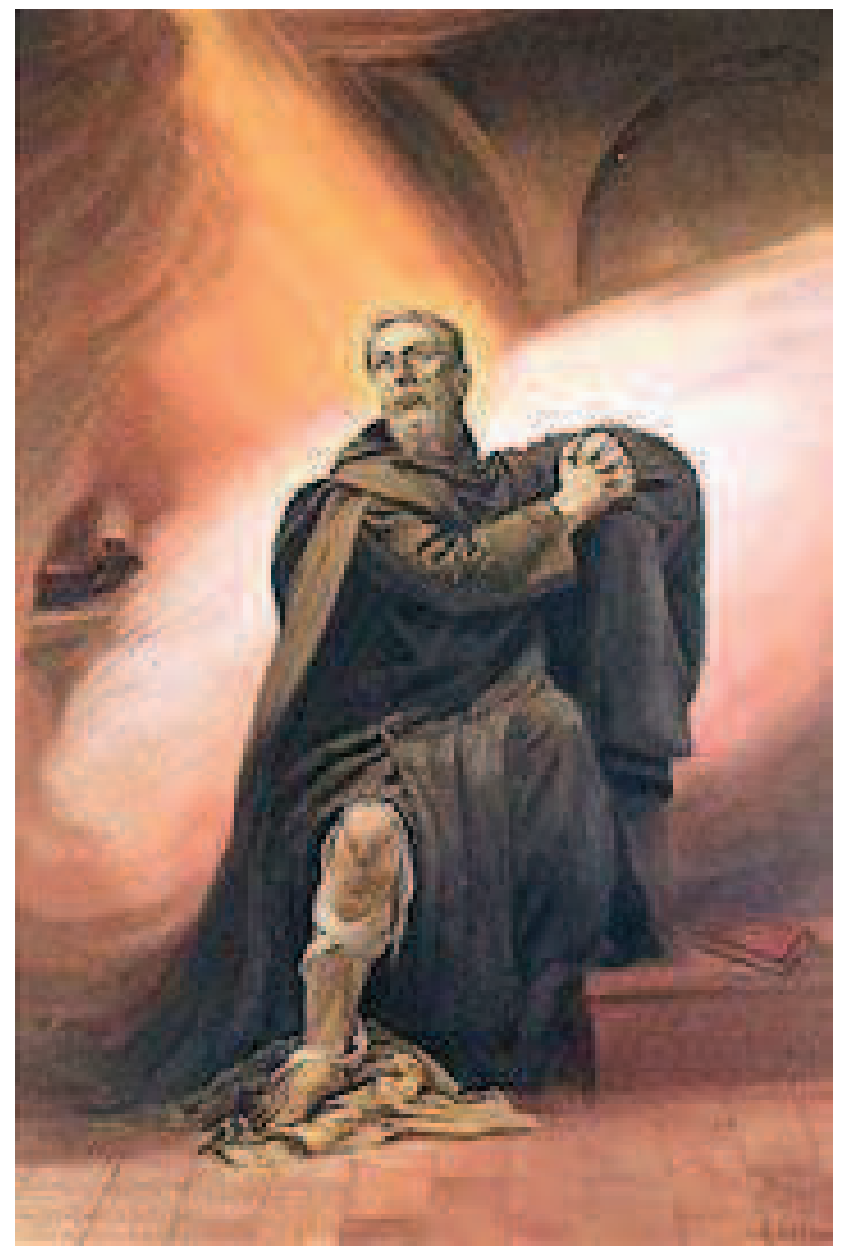

Figure 2 - St Peregrine's iconography showing a chronic leg lesion treated with bandages. (by permission: Francesco Diani - Redazione LaChiesa.it)

Surprisingly, even in an active mobile subject edemaprotective effect of the musculovenous pump could only be shown in about $50 \%$ of the subjects, while rather muscle contractions activate mechanisms that stimulate the extravasation of fluid. In nearly all cases, the calf volume was greater in the evening than in the morning 8 .

In normal conditions, in a perfectly healthy subject living an unlikely ideal balanced life an edema will represent an exception as all the defense mechanism will be in action, however everyday life will probably not be able to satisfy this request so that HP effects will prevail with high probability to alter the instable balance of the same defense mechanisms.

In particular, episodes of venous hypertension more or less lasting are very frequent in modern lifestyle (standing or sitting at work, overweight, not suitable shoes, limited deambulation, long flights, Valsalva needing sports, and more). Maybe, the long-term hydrostatic effect as volume change only without the chronic inflammatory changes will not lead into ulcer formation, but these inflammatory changes may result from many common borderline disorders (reflux, obstruction, obesity, foot static disorders, musculo-skeletal diseases etc) accompanying "normal" people's life.

The patient of the photo is a worker standing probably for many hours at the foundry, in a very hot atmosphere and these elements create the condition of no compensated venous hypertension at the lower limbs so that the foot lesion is destined to heal more slowly than in hand.

The same mechanism, but in a more dramatic proportion, explains the anecdotal evolution of $\mathrm{St}$ Peregrine's pathology (varices with no healing secreting bad-smelling ulcer. (Fig 2) connected to the legendary telling that for thirty years he was never seen sitting even when praying or eating, leaning against a rock for a quick sleep or rest. A miracle healed the lesion in a night time ${ }^{9}$. Astonishingly, only one leg was affected, but in front of saints and miracles nothing can be objected.

\section{References}

1) Lee BB et al. Venous Hemodynamic Changes in Lower Limb Venous Disease: the UIP Consensus According to Scientific Evidence. Int Angiol 2016 June;35(3):236-352.

2) Pannier F, Rabe E. Optoelectric volume measurements to demonstrate volume changes in the lower extremities during orthostasis. Int Angiol 2010 October;29(5):395-400.

3) Brown CM, Hainsworth R. Assessment of capillary fluid shifts during orthostatic stress in normal subjects and subjects with orthostatic intolerance. Clin Auton Res. 1999 Apr;9(2):69-73.

4) Hagan RD, Diaz FJ, Horvath SM. Plasma volume changes with movement to supine and standing positions. J Appl. Physiol. 45:414-418, 1978.

5) Jacob G, Ertl AC, Shannon JR, Furlan R, Robertson RM, Robertson D. Effect of standing on neurohumoral responses and plasma volume in healthy subjects. J Appl. Physiol. 84(3): 914-921, 1998

6) Masoud M, Sarig G, Brenner B, Jacob G. Orthostatic Hypercoagulability: A Novel Physiological Mechanism to Activate the Coagulation System. Hypertension. 2008;51:1545-1551.

7) Scallan J, Huxley VH, Korthuis RJ. Capillary Fluid Exchange: Regulation, Functions, and Pathology. Chapter 4: Pathophysiology of Edema Formation. San Rafael (CA): Morgan \& Claypool Life Sciences; 2010.

8) Stick C, Stöfen P, Witzleb E. On physiological edema in man's lower extremity. Eur J Appl Physiol Occup Physiol. $1985 ; 54: 442-9$.

9) Vita Beati Peregrini Foroliviensis ordinis servorum Sanctae Mariae [Life of the Consecrated Peregrine from Forlì of the Servites Order], written before 1483 by the Sienese humanist Niccolò Borghese. 